\title{
PROCAINE AMIDE IN THE CONTROL OF CARDIAC ARRHYTHMIAS
}

BY

\author{
B. G. B. LUCAS AND D. S. SHORT \\ From the National Heart Hospital \\ Received March 21, 1952
}

Recent developments in cardiac surgery and modern methods of cardiac investigation have emphasized the need for a drug that will control the irritability of the heart, particularly ventricular arrhythmias. In clinical cardiology also a satisfactory drug for the treatment of ventricular tachycardia has still to be found, one, moreover, that can be administered parenterally with safety. The usefulness of procaine has been limited by its side effects, hypotension and excessive central nervous stimulation. The amide of procaine has not these disadvantages to the same degree, and early reports (Mark et al., 1950; Newman and Clark, 1950) have emphasized its value in the control of arrhythmias. It is the purpose of this paper to report on the efficacy of procaine amide in the control both of clinical arrhythmias and of those occurring during mechanical interference with the heart, either during cardiac catheterization or during cardiac surgery.

\section{Clinical Arrhythmias}

Procaine amide* was administered to fifty-six patients, three of whom had two types of arrhythmia; five with ventricular tachycardia, eighteen with ventricular extrasystoles, eleven with supraventricular tachycardia, six with supraventricular extrasystoles, eighteen with auricular fibrillation, and one with auricular flutter. It was used both to treat current arrhythmias and to prevent recurrence. Intravenous and oral routes of administration were employed, although in order to obtain unequivocal results, the intravenous route was preferred. The dose did not exceed $1 \mathrm{~g}$. intravenously or $4 \mathrm{~g}$. daily by mouth. The results are shown in the table.

Ventricular Tachycardia. Five patients with ventricular tachycardia were treated by procaine amide $0.25 \mathrm{~g}$. to $0.6 \mathrm{~g}$. Success was achieved in four and in these the mode of reversion to sinus rhythm was studied. Three showed an abrupt cessation of the tachycardia followed by a short period during which the sinus rhythm was interrupted by frequent ventricular extrasystoles. In the fourth, sinus complexes gradually replaced the ectopic beats. The only failure was a patient with complete heart block in whom the dose was limited to $0 \cdot 3 \mathrm{~g}$. This was the only case of known ischæmic origin.

Ventricular Extrasystoles. Ventricular extrasystoles were also abolished by small doses of procaine amide administered intravenously. They disappeared within a few minutes of the end of the injection but reappeared forty minutes to two hours later. Therapy by the oral route was successful in seven out of thirteen instances. In three others the number of extrasystoles was reduced, but in one no effect was noticed after $2.5 \mathrm{~g}$. Success was unrelated to the electrocardiographic pattern or to the ætiology. In six patients the arrhythmia was associated with ischæmic heart disease and in four with digitalis therapy; in the remainder the ætiology was uncertain.

Supraventricular Tachycardia. Four out of nine episodes of supraventricular tachycardia were terminated; one by oral administration. In three of the eight patients, the arrhythmia was apparently nodal in origin; one was suppressed for twenty minutes only and the other two were slowed

* The procaine amide (pronestyl) used in this investigation was supplied by E. R. Squibb \& Sons. 
Treatment of ARrhythmias

\begin{tabular}{|c|c|c|c|c|c|c|c|c|c|}
\hline \multirow[b]{2}{*}{ Arrhythmia } & \multicolumn{6}{|c|}{ Termination } & \multicolumn{3}{|c|}{ Prevention } \\
\hline & Cases & $\begin{array}{l}\text { Epi- } \\
\text { sodes }\end{array}$ & Route & No. & $\begin{array}{l}\text { Suc- } \\
\text { cess }\end{array}$ & $\begin{array}{l}\text { Successful } \\
\text { dose }(\mathrm{g})\end{array}$ & No. & $\begin{array}{l}\text { Suc- } \\
\text { cess }\end{array}$ & $\begin{array}{c}\text { Successful } \\
\text { dose }(\mathrm{g})\end{array}$ \\
\hline \multirow{2}{*}{ Ventricular tachycardia } & \multirow{2}{*}{5} & \multirow{2}{*}{8} & $1 . \mathrm{V}$. & 5 & 4 & $0.25-0.6$ & \multirow{2}{*}{4} & \multirow{2}{*}{1} & \multirow{2}{*}{0.5 t.i.d. } \\
\hline & & & oral & 3 & 1 & 0.75 & & & \\
\hline \multirow{2}{*}{ Ventricular extrasystoles } & \multirow{2}{*}{18} & \multirow{2}{*}{18} & I.V. & 5 & 5 & $0.2-0 \cdot 5$ & \multirow{2}{*}{9} & \multirow{2}{*}{4} & \multirow{2}{*}{$0.5-1.0$ t.i.d. } \\
\hline & & & oral & 13 & 7 & $0 \cdot 5-1 \cdot 0$ & & & \\
\hline \multirow{2}{*}{ Supraventricular tachycardia } & \multirow{2}{*}{8} & \multirow{2}{*}{9} & I.V. & 7 & $3^{*}$ & $0.2-0.8$ & \multirow{2}{*}{6} & \multirow{2}{*}{-} & \\
\hline & & & oral & 2 & 1 & $3.0 \mathrm{in} 24 \mathrm{hr}$. & & & \\
\hline \multirow{2}{*}{ Supraventricular extrasystoles } & \multirow{2}{*}{6} & \multirow{2}{*}{6} & I.V. & 3 & 2 & $0.45 \& 0.5$ & \multirow{2}{*}{2} & \multirow{2}{*}{ - } & \\
\hline & & & oral & 3 & - & & & & \\
\hline \multirow{2}{*}{ Auricular fibrillation } & \multirow{2}{*}{18} & \multirow{2}{*}{19} & I.V. & 10 & 2 & $0.5 \& 0.7$ & \multirow{2}{*}{-} & & \\
\hline & & & oral & 9 & 1 & $2.5 \mathrm{in} 2 \mathrm{hr}$. & & & \\
\hline \multirow{2}{*}{ Auricular flutter } & \multirow{2}{*}{1} & \multirow{2}{*}{1} & I.V. & 1 & - & & \multirow{2}{*}{-} & & \\
\hline & & & oral & - & & & & & \\
\hline
\end{tabular}

* In one other patient the arrhythmia was terminated by carotid sinus pressure following the intravenous administration of $0.5 \mathrm{~g}$. of procaine amide. Carotid sinus pressure beforehand had failed.

without being terminated. In one patient in whom auricular tachycardia was known to have been present for many weeks, the oral administration of $3 \mathrm{~g}$. of procaine amide in twenty-four hours was followed by a Stokes-Adams attack, a period of slow nodal rhythm preceding the establishment of sinus bradycardia. It was discovered subsequently that a similar occurrence had followed treatment with large doses of quinidine.

Supraventricular Extrasystoles. Supraventricular extrasystoles were abolished in two out of six instances, on both occasions by intravenous administration. In one patient with sinus bradycardia who was showing frequent nodal escape, the administration of $0.8 \mathrm{~g}$. intravenously resulted in nodal rhythm due to temporary suppression of sinus activity.

Auricular Fibrillation. Of eighteen patients with auricular fibrillation, sinus rhythm was restored in three in whom the arrhythmia had been present for less than seven days. In the remainder the auricular rate was retarded.

Auricular Flutter. In the one patient with auricular flutter the paroxysm terminated fortyfive minutes after intravenous administration of procaine amide, but since by this time the peak effect on the auricular rate was past, this result is regarded as probably coincidental.

Prophylactic Treatment. In the prophylaxis against recurrence no effect was observed on any of the six patients with supraventricular tachycardia or on the two with auricular extrasystoles. Of four patients with repeated attacks of ventricular tachycardia satisfactory control was obtained in one; in another there was a reduction in the number of attacks. Ventricular extrasystoles were abolished in four out of nine patients, satisfactory control being maintained in one for five months. In two of the remainder, although some reduction was noted initially, it was not maintained.

\section{Cardiac Catheterization}

Twenty-eight patients were studied: thirteen with mitral stenosis (six with auricular fibrillation being digitalized), eleven with congenital heart disease, and four others. Right heart catheterization 
was performed under local anæsthesia after premedication with sodium amytal. Pressures were recorded with an electro-manometer, mean pressures being determined by electrical integration. The electrocardiogram, which was observed continuously, was recorded when abnormalities were noticed and when the catheter was in the right ventricle.

Initially procaine amide was given to six patients in order to determine its effect on pulmonary artery pressures. The dose varied from $0.25 \mathrm{~g}$. to $0.5 \mathrm{~g}$. In five (mean pressures $60,55,36,34$, and $7 \mathrm{~mm} . \mathrm{Hg}$ ), there was a fall and in one (mean pressure $27 \mathrm{~mm}$.) a rise, but in none did the variation exceed $5 \mathrm{~mm}$. In one the pulmonary artery pressure recorded for twelve minutes before administration showed a variation of $4 \mathrm{~mm}$.

Ventricular extrasystoles occur most frequently when the tip of the catheter is at the tricuspid area or in the right ventricular outflow tract. When extrasystoles occurred at this stage in three selected patients premedicated with quinidine 3 grains, the catheter was withdrawn and procaine amide, $0.5 \mathrm{~g}$. to $0.75 \mathrm{~g}$., administered intravenously. After five minutes the procedure was repeated. In one the drug had no effect; in another the number of ventricular extrasystoles was halved and in the third they disappeared, but reappeared spontaneously twenty-five minutes later, after the catheter had been withdrawn.

Procaine amide was then given intravenously to ten patients as soon as the catheter had been inserted. The dose varied from $0.25 \mathrm{~g}$. to $0.5 \mathrm{~g}$. Ventricular extrasystoles were observed in eight; four had paroxysms persisting for seven or more beats, one as long as nineteen beats.

Finally, procaine amide was administered orally to fifteen patients half an hour before catheterization in a dose varying from $0.5 \mathrm{~g}$. to $1 \mathrm{~g}$. Ventricular extrasystoles were observed in twelve, four having paroxysms which persisted for seven or more beats, the longest being thirteen (Fig. 1).

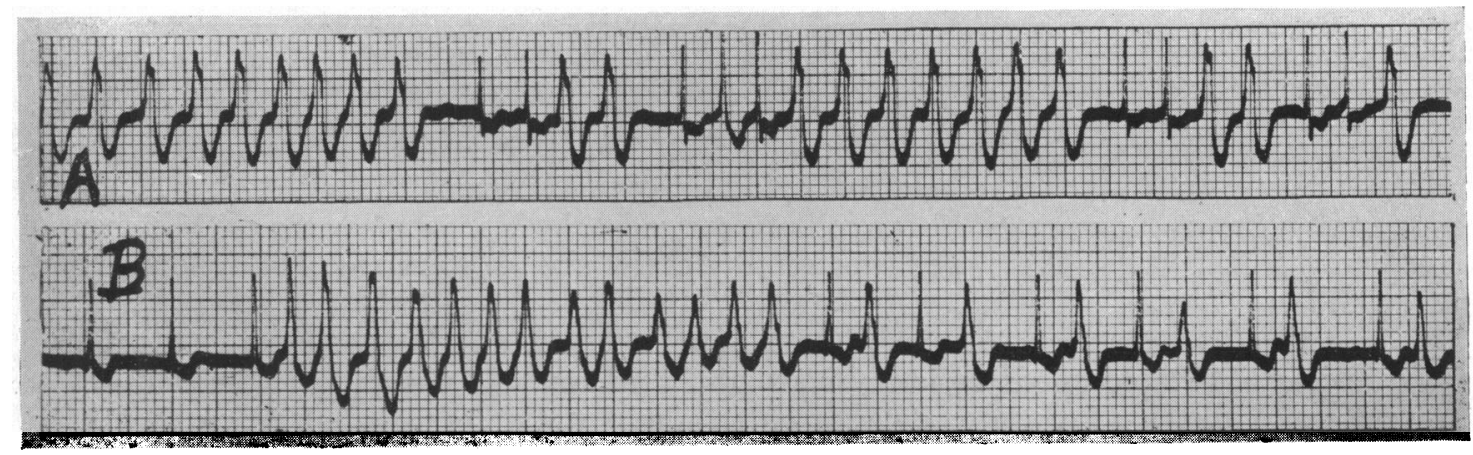

Fig. 1.-Ventricular arrhythmias during cardiac catheterization. (A) 25 minutes after procaine amide $0 \cdot 5 \mathrm{~g}$. intravenously. (B) 60 minutes after procaine amide $1.0 \mathrm{~g}$. orally.

\section{CARDiac SURgery}

Patients undergoing direct heart operations were selected for study. All were anæsthetized with the same technique: omnopon and scopolamine premedication; induction with thiopentone and curare, and maintenance with nitrous oxide and oxygen, using a controlled respiration technique. Further doses of thiopentone and curare were administered as required. Prior to the opening of the pericardium 2 to $5 \mathrm{ml}$. of 0.25 per cent amethocaine was instilled into it and the heart itself was infiltrated with 1 per cent procaine around the area of incision. The electrocardiogram was observed continuously and was recorded when abnormalities were noticed and during the endocardial manœuvres.

The effect of intravenous procaine amide on the arrhythmias that occur during manipulation of the heart was studied in twenty-four patients: sixteen with mitral stenosis and eight with cyanotic congenital heart disease. The dose varied from $0.1 \mathrm{~g}$. to $0.5 \mathrm{~g}$. according to body weight. Those with mitral stenosis were digitalized at the time of operation, with the exception of four who received 
quinidine, 5 to 10 grains, preoperatively. Six patients with cyanotic congenital heart disease also received quinidine, 1 to 5 grains, the other two being given oral procaine amide, $0.25 \mathrm{~g}$. and $0.5 \mathrm{~g}$.

Following the administration of procaine amide, ventricular ectopic beats were observed in nine of the patients with mitral stenosis. These varied from a few while the heart was being manipulated to paroxysms of ventricular tachycardia necessitating the abandonment of the operative manœuvre. Ventricular ectopic beats were also observed in seven of the eight patients with cyanotic congenital heart disease.

\section{ToXIC EFFECTS}

Apart from gastro-intestinal disturbances and hypotension, no important toxic effects were observed throughout this investigation, nor were any significant changes found in the electrocardiogram. Nausea and vomiting occurred in a proportion of the twenty-four patients who received prolonged oral administration of procaine amide and in six these symptoms were severe enough to necessitate withdrawal of the drug although in two the dose did not exceed $0.5 \mathrm{~g}$. t.i.d. In two others nausea and vomiting occurred at the outset, but disappeared spontaneously despite continued therapy.

A fall of blood pressure was frequently observed following intravenous administration and a special study of this was made on thirty occasions when the drug was given by this route. In twentytwo instances the dose did not exceed $0.7 \mathrm{~g}$.; in nine there was no fall of blood pressure, in four a fall of up to 10 per cent and in nine a fall of 10 to 25 per cent. Eight patients received $0.75 \mathrm{~g}$. to $1 \mathrm{~g}$.; a fall of between 10 and 25 per cent occurred in three and 30 to 40 per cent in five. There was no apparent correlation between speed of administration and hypotensive effect.

\section{Discussion}

An analysis of four papers (Kayden et al., 1951; Miller et al., 1951; Berry et al., 1951; Kinsman et al., 1951) reporting 279 cases of clinical arrhythmia treated with procaine amide shows that ventricular tachycardia was terminated in 69 per cent, ventricular extrasystoles in 91 per cent, supraventricular tachycardia in 68 per cent, auricular fibrillation in 7 per cent, and auricular flutter in 5 per cent. The treatment of auricular fibrillation was successful only if it was of recent origin. The present investigation supports this analysis.

Corresponding figures relating to the prophylaxis of arrhythmias are not available. In the present series procaine amide was uniformly unsuccessful in preventing supraventricular arrhythmias and only succeeded in a minority of ventricular arrhythmias. In some patients, however, ventricular extrasystoles were suppressed for periods of one to five months. The failure of oral procaine amide to achieve long-term control may be related to its rate of removal from the blood-stream which is approximately twice as rapid as that of quinidine (Mark et al., 1951). In a significant proportion of patients, the maintenance of a therapeutic blood level was prevented by vomiting.

The fact that procaine amide slows the auricular rate in auricular fibrillation is in agreement with the view that its action resembles that of quinidine (Newman and Clark, 1951; Wedd et al., 1951), and implies a need for caution in the presence of conduction defects. In the present investigation the administration of the drug to two patients with sino-auricular block led to auricular standstill. It is interesting that two patients whose attacks of ventricular tachycardia were terminated by procaine amide had failed repeatedly to respond to quinidine in full dosage. On the other hand, quinidine was effective in two patients with paroxysmal supraventricular tachycardia and one with multiple auricular extrasystoles in which procaine amide failed.

\section{SUMMARY AND CONCLUSIONS}

This investigation, based on the treatment of 56 patients with clinical arrhythmias, 28 patients undergoing cardiac catheterization, and 24 patients submitted to cardiac surgery, has confirmed the 
value of procaine amide in the termination of paroxysmal tachycardia. It has also confirmed the safety of the intravenous route of administration provided the hypotensive effect of large doses is borne in mind.

Procaine amide is of limited value in the prophylaxis of clinical arrhythmias and of no value in the prevention of the arrhythmias arising during mechanical interference with the heart.

We are grateful to the Physicians of the National Heart Hospital and especially Dr. Paul Wood for their help and to Mr. J. Brabrook-Norman for his technical assistance in this investigation.

\section{REFERENCES}

Berry, K., Garlett, E. L., Bellet, S., and Gefter, W. I. (1951). Amer. J. Med., 11, 431.

Kayden, H. J., Steele, J. M., Mark, L. C., and Brodie, B. B. (1951). Circulation, 4, 13.

Kinsman, J. M., Hansen, W. R., and McClendon, R. L. (1951). Amer. J. med. Sci., 222, 365.

Mark, L. C., Berlin, I., Kayden, H. J., Rovenstine, E. A., Steel, J. M., and Brodie, B. B. (1950). J. Pharmacol., 98, 21.

-, Kayden, H. J., Steele, J. M., Cooper, J. R., Berlin, J., Rovenstine, E. A., and Brodie, B. B. (1951). J. Pharmacol., 102, 5.

Miller, H., Nathanson, M. H., and Griffith, G. C. (1951). J. Amer. med. Ass., 146, 1004.

Newman, P. J., and Clark, B. B. (1950). Fed. Proc., 9, 304.

Wed, (1951). Fed. Proc., 10, 326.

Wedd, A. M., Blair, H. A., and Warner, R. S. (1951). Amer. Heart J., 42, 399. 